\title{
Editorial
}

\section{Clinic practices}

Those working in clinics for the treatment of sexually transmitted diseases (STDs) have a long history of critical self-appraisal, and reports on the findings have regularly appeared in the British Journal of Venereal Diseases. Larger scale surveys have also been conducted by the British Co-operative Clinical Group and great credit should be paid to Dr R. R. Willcox for all the work he has done compiling reports on their activities. On page 2 we publish the first of a series of reports from Dr M. W. Adler and his colleagues from the Medical Research Council's Group on Sexually Transmitted Diseases at the Middlesex Hospital, London, on a survey that has been conducted into the work of clinics in England and Wales. This is a valuable extension of the work done by the British Co-operative Clinical Group.

This report shows the high standards of clinical care given to patients attending most of the clinics. One aspect of care does give cause for concern; in a few clinics nurses are allowed to examine, investigate, and prescribe treatment for patients after consulting with the doctor by telephone. Many of these nurses are competent and provide a good service. While this is in line with the expanding role of clinical nurses (Department of Health and Social Security, 1977), it does not necessarily accord with the provision of the highest standards of clinical care. Clinics where this occurred were open for a mean of 17 hours, compared with a mean of $14 \frac{1}{2}$ hours for all clinics. It might be asked if these long opening hours, some without a doctor in the clinic, are really in patients' best interests, and it is hoped that consultants in charge of these clinics are striving to obtain more doctors' services to cover the clinics. These consultants deserve the strongest support in their efforts to obtain staff. Furthermore the role of the nurse in STD clinics needs further investigation.

In countries where there is still a shortage of doctors, particularly in areas remote from centres of excellence, nurses may be the only staff available to treat cases of STD and may supply a good service to their patients. It is hoped that in due course standards can be raised and the service improved in these areas.

In the second paper, on page 10, Dr Adler shows that the standards of diagnosis of gonorrhoea are reasonably uniform. In contrast, in the third paper, page 15, he describes the wide variety of treatments prescribed for uncomplicated gonorrhoea. This variation has been remarked on by visitors from overseas to clinics in this country and has even caused confusion to some of them. It is vitally important that those in charge of clinics monitor the results of their treatment. Provided satisfactory cure rates are maintained, and most authorities would regard cure rates for uncomplicated gonorrhoea of $95 \%$ or higher as satisfactory, this is a healthy state of affairs. This variation in treatment contrasts with more rigid recommendations in some other countries. While there are certain advantages to such recommendations, they may limit the scope for experiment, remove initiative from the treating physician, and with rapidly changing patterns of gonococcal antibiotic sensitivity patterns, they may lead to a sense of false security.

It is also hoped that the findings in Dr Adler's third paper, on page 19, will help all physicians to review their own criteria for reporting cases. The totals compiled in the United Kingdom depend on the accuracy of the returns from the clinics, and it is apparent that there is variation between clinics in some criteria.

Reference
Department of Health and Social Security (1977). Health Services
Management: The Extending Role of the Clinical Nurse-Legal Management: The Extending Role of the Clinical Nurse-L
Implications and Training Requirements. Circular HC (77) 22. 